\title{
Assessment of Imaging Spectroscopy for rock identification in the Karkonosze Mountains, Poland
}

Abstract

Based on laboratory, field and airborne-acquired hyperspectral data, this paper aims to analyse the dominant minerals and rocks found in the Polish Karkonosze Mountains. Laboratory spectral characteristics were measured with the ASD FieldSpec 3 spectrometer and images were obtained from VITO's Airborne Prism EXperiment (APEX) scanner. The terrain is covered mainly by lichens or vascular plants creating significant difficulties for rock identification. However, hyperspectral airborne imagery allowed for subpixel classifications of different types of granites, hornfels and mica schist within the research area. The hyperspectral data enabled geological mapping of bare ground that had been masked out using three advanced algorithms: Spectral Angle Mapper, Linear Spectral Unmixing and Matched Filtering. Though all three methods produced positive results, the Matched Filtering method proved to be the most effective. The result of this study was a set of maps and post classification statistical data of rock distribution in the area, one for each method of classification.

Keywords

Rock identification - Imaging Spectroscopy • APEX hyperspectral airborne imagery data - Spectral Angle Mapper - Linear Spectral Unmixing • Matched Filtering

(C) University of Warsaw - Faculty of Geography and Regional Studies
Monika Mierczyk ${ }^{1}$, Bogdan Zagajewski ${ }^{1}$, Anna Jarocińska ${ }^{1}$, Roksana Knapik ${ }^{2}$

'Department of Geoinformatics, Cartography and Remote Sensing, Faculty of Geography and Regional Studies, University of Warsaw, Poland e-mail: monika.mierczyk@gmail.com e-mail: bogdan@uw.edu.pl e-mail: ajarocinska@uw.edu.pl

2Karkonosze National Park, Poland e-mail: roksana@kpnmab.p

Received: 20 May 2015

Accepted: 20 August 2015

\section{Introduction}

The remote identification of rocks and minerals in the 1980s began the era of Imaging Spectroscopy (Goetz et al. 1985). This technique uses the simultaneous acquisition of images in many spectrally narrow and contiguous bands. Today it provides an efficient method for exploring and mapping surface mineralogy by means of advanced algorithms and processes.

The image classification was based on three algorithms: Spectral Angle Mapper (SAM), Linear Spectral Unmixing (LSU) and Matched Filtering (MF). The first method calculates an angle between a pixel and a reference spectrum, treating them as vectors (Yuhas et al. 1992). The LSU and MF subpixel classifiers produce images of each class (rock) abundance (Adams et al. 1995). This provided classification maps with threshold values freely created by the user (Zayas-Santiago 2009).

The application of hyperspectral data in rock identification began in the 1980s with the Alexander F.H. Goetz's study (1985) at the California Institute of Technology. The term 'hyperspectral data' first appeared in Science magazine, which described it as 'acquiring images simultaneously in 100 to 200 contiguous spectral bands' (Goetz et al. 1985). In 1999 R. N. Clark from the United States Geological Survey (USGS) published his research presenting spectral libraries of the most popular types of minerals, rocks and other chemical compounds. The author indicated absorption lines that allowed for the differentiation and identification of materials and connected them to typical physiochemical features (Clark 1999).

Recently, many studies that focus on remote detection have been undertaken, and the main assignment has been spectral classification using Spectral Angle Mapper, Linear Spectral Unmixing, Marched Filtering or Mixture Tuned Matched Filtering algorithms coupled with aerial hyperspectral images (Charou et al. 2007; Gabr et al. 2010; Lau et al. 2003; Zayas-Santiago 2009).

The Mixture Tuned Matched Filtering algorithm applied to AVIRIS aerial imagery was used in the Argentinian Los Menucos gold district (Kruse et al. 2006). This study featured a research area with similar vegetation cover to the Karkonosze Mountains. As was shown in this study, the ASD Field Spec data helped to validate and refine the classification results.

Since hyperspectral technology has been used in geologic research, the benefits of hyperspectral imaging for the mining industry has become more and more apparent (Kruse 1996, Cudahy et al. 2001). Integrating geology with hyperspectral data has been used for precious metals and minerals exploration, for example uranium and gold (Shalaby 2010. HyVista 2012). Growing interest and exploration within the geothermal sector have paved the way for the use of hyperspectral tools for detecting the distribution of alteration minerals and therefore mapping geothermal and hydrothermal sources (Martini et al. 2003, Littlefield \& Calvin 2013).

Together, these studies have covered multiple applications for hyperspectral rock identification, from scientific to industrial. This study seeks to introduce the newly-acquired, high-resolution, APEX imaging data to recognise rock samples commonly found in the mountains of Poland. Given the research area, the findings and methods of this study may also be applicable to future research based on other European mountain ranges with comparable patterns of geology and vegetation. 


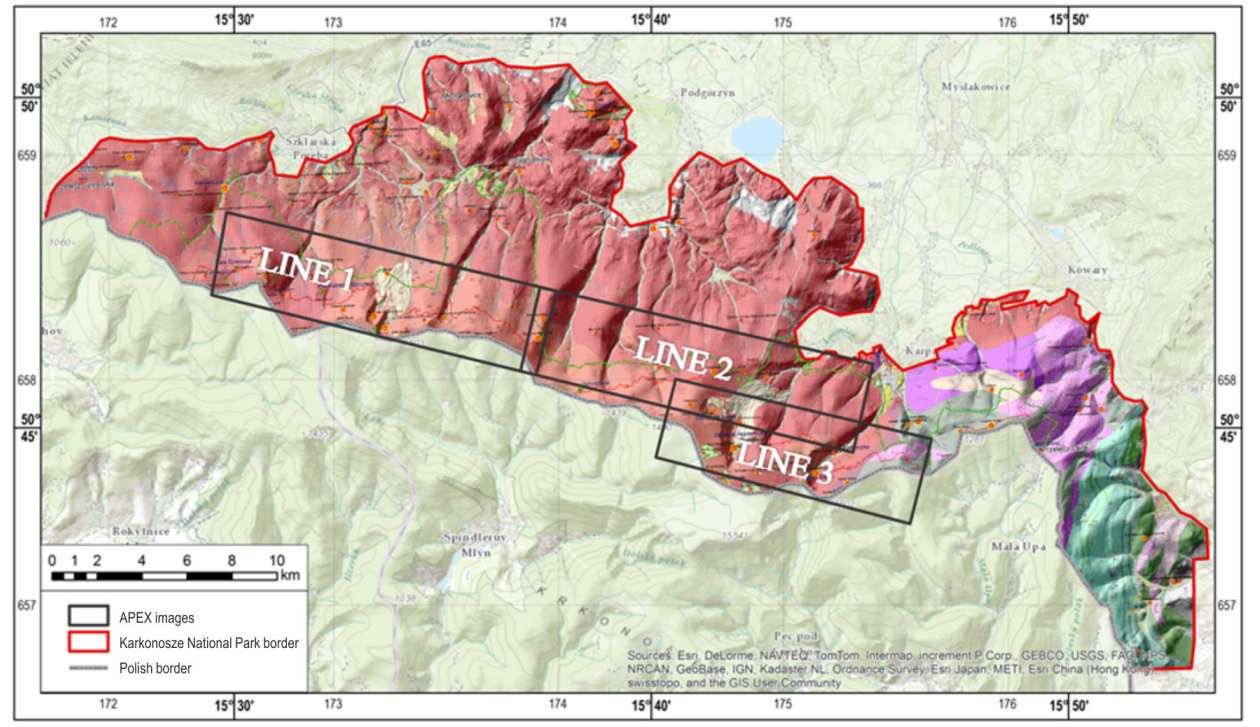

Figure 1. The study area: three image lines applied to the geological map of the Karkonosze National Park

a)
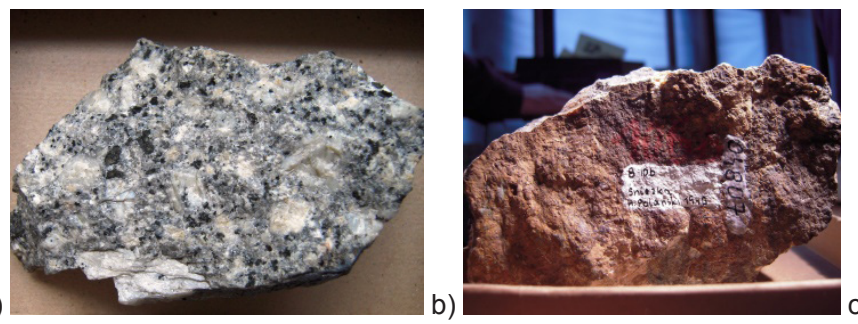
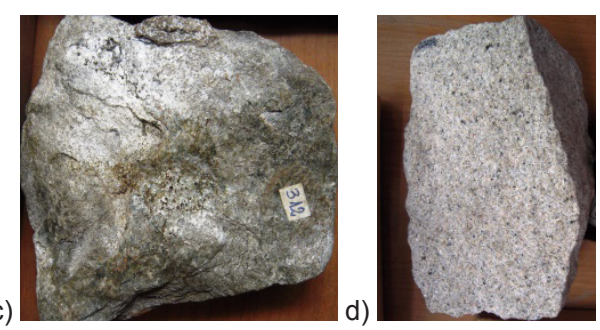

Figure 2. Mineral and rock samples from the laboratory analysis: a) porphyritic granite, b) hornfels, c) mica schist, d) equigranular granite (photographs: Monika Mierczyk)

Research area and geology

The research area is located in south-west Poland in part of the Sudetes range: the Karkonosze Mountains. The terrain is complex and rock interpretation is affected by thick vegetation and lichens (Macko 1970) and the presence of the chlorophyll modifies the reflectance of the images (Zagajewski et al. 2010). Moreover, climate conditions determine the water content of plants and the air, which absorbs electromagnetic radiation in the infrared spectrum. The disturbances caused by the reflection affect the adjacent spectral ranges due to the vibrations and rotations of the water elements (Belward 1991).

Nevertheless, peaks and rock outcrops allowed for useful image analysis. Even small areas of exposed bedrock produced positive results for the research. Igneous and metamorphic rocks are distributed on the boundary of the Karkonosze National Park. The widest outcrops comprise granite as well as hornfels and mica schist (Kozłowski, Sachanbiński 2007). A geological map on a scale of $1: 36000$, produced by the Karkonosze National Park (Aleksandrowski et al. 2009, Fig 1.), was used to analyse the geological composition of the research area. Based on this material, four classes of rocks were chosen: equigranular granite, porphyritic granite (with larger crystals of alkaline feldspar than the equigranular form), hornfels and mica schist.

\section{ASD FieldSpec 3 laboratory data}

The initial part of the research involved the laboratory analysis of mineral and rock specimens sourced from the Karkonosze
Mountains. An ASD FieldSpec 3 portable spectrometer with a spectral range of $350-2500 \mathrm{~nm}$ and ASD ProLamps as the light source were used. The measurement of reflectance began with the 25 Dark Current and 25 White Reference (Spectralon) calibration records for the device. Every mineral and rock was measured from 8-39 times from different angles and each measurement comprised 25 automatically-averaged values. Dozens of rock and mineral specimens were spectrally and statistically tested. For spectrally similar samples, the ANOVA statistical test was applied to indicate statistically significant differences in absorption features in different electromagnetic spectra.

\section{APEX data and processing}

Access to aerial images taken by a Dornier Do228 DLR airplane on the $10^{\text {th }}$ of September 2012 formed the genesis of this study, i.e. rock identification in the Karkonosze Mountains. As part of the EUFAR TA HyMountEcos project, field and airborne data was sourced from the DLR and VITO flight programs with the use of the Airborne Prism EXperiment (APEX) scanner. Hyperspectral images use 288 contiguous bands with a high spatial resolution of 1.75 meters. Geometric processing procedures were conducted by VITO at its facilities and corrected images were delivered to the University of Warsaw. This study attempted to detect rocks on bare, vegetation-free ground in the Karkonosze Mountains for three images. The image classification was based on three spectral methods: Spectral Angle Mapper (SAM), 
Linear Spectral Unmixing (LSU) and Matched Filtering (MF). In the study, a geological map of the Karkonosze National Park, photointerpretation of APEX data applying RGB Colour Infrared (CIR) composition and an NDVI mask were applied. Each image was processed with each of the three spectral methods, which produced three geological maps of the terrain. The selected post-classification analysis helped to assess the accuracy of classifications and design proper cartographic products.

The detailed method scheme of the preceding steps is presented in Figure 3.

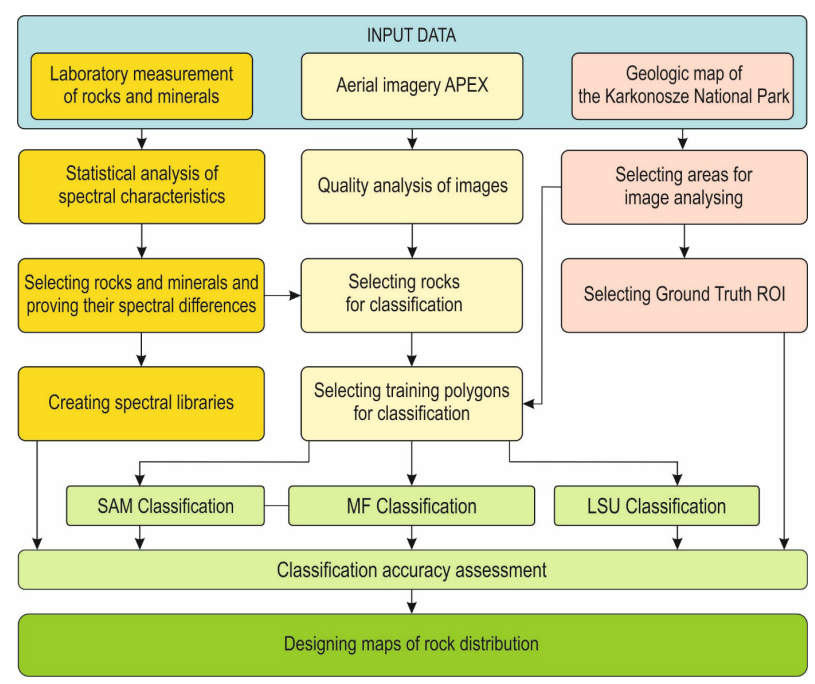

Figure 3. Method scheme for the research, based on three columns of three types of data dealing with analysing, processing and accuracy assessment, and culminating in maps of rock distribution
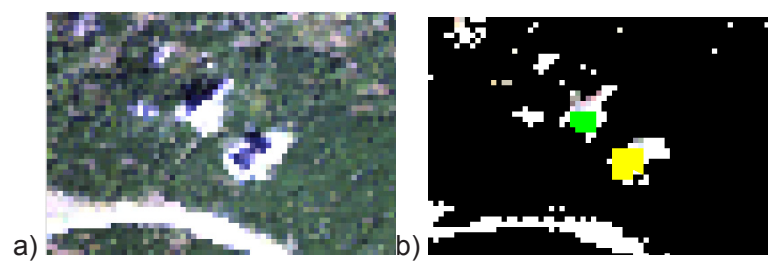

Figure 4. Image a) presents a clip of a raw aerial photo whereas image b) shows a photo with an NDVI mask (black) as well as testing and verifying polygons (green and yellow respectively) (photographs: Monika Mierczyk)
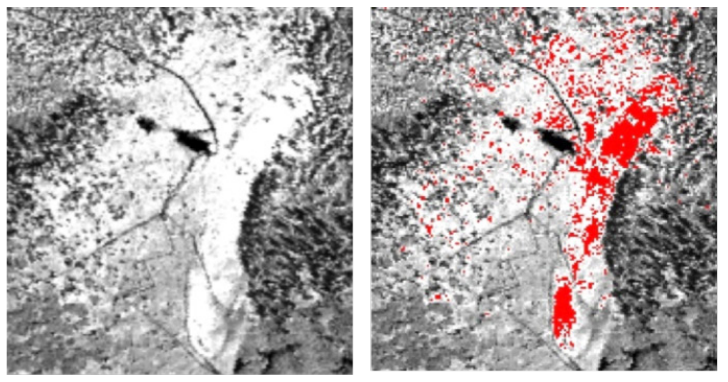

For classification, test polygons were used consisting of at least 180 pixels for each class, and verifying polygons covering a double area of pixels. Paths and trails in the region were excluded from the visual interpretation since their surface material was possibly sourced from local rock quarries. An example of the polygons is presented in Figure 4.

Three spectral methods of classification were applied to the aerial hyperspectral imagery: Spectral Angle Mapper (SAM), Linear Spectral Unmixing (LSU) and Matched Filtering (MF). The first algorithm determines the spectral similarity between analysed and reference spectra (Yuhas et al. 1992). The SAM method calculates the angle between the spectra, treating them as vectors in an $n$-dimensional space where $n$ is equal to the number of bands. The angle is a variable value in radians and influences the result of the classified pixels. The larger the value of the angle the more significant the difference in comparison to the reference spectra.

Subpixel methods: LSU and MF, produce output images of the abundance values of each endmember (Adams et al. 1995). The end result is the fractional value of each pattern spectra in a pixel. The linear unmixing method indicates a linear combination of the reflectance of each endmember present within the pixel. The MF algorithm maximizes the response of the known endmember and suppresses the response of the unknown composite background. In subpixel methods thresholding values is an essential stage of the classification. As demonstrated in Figure 5 the wider the range of values, the larger the areas of pixels that are classified.

An existing geological map was the source for testing and verifying polygons that were marked on the bare rocks. NDVI masks with a value higher than 0.3 were applied to each image in order to exclude vegetation areas.

The post-classification process - generalization - helped to clump classes and eliminate single pixels. The Clump classes method smoothed image results and reduced holes in classified areas, whereas Majority Analysis transformed single false pixels, within a large class, to that class. The parameters applied in both methods were chosen individually after calculating classification accuracies. The accuracy of the classification images was assessed by comparing the acquired rock distribution images to the ground truth polygons represented on the geological map areas of each class occurrence.

\section{Results and conclusions}

The spectral characteristics of all four samples (porphyritic granites, hornfels, mica schists and equiregular granites) are different (Figure 6). The spectral value curves of the rock samples are set with the standard deviation and prove that all samples are statistically different. Three significance levels were set: 0.001 , $0.05,0.01$. Even the equigranular granite characteristic and the hornfels line have certain distinctive ranges of the spectrum. The laboratory results opened the way for the next stage of research.
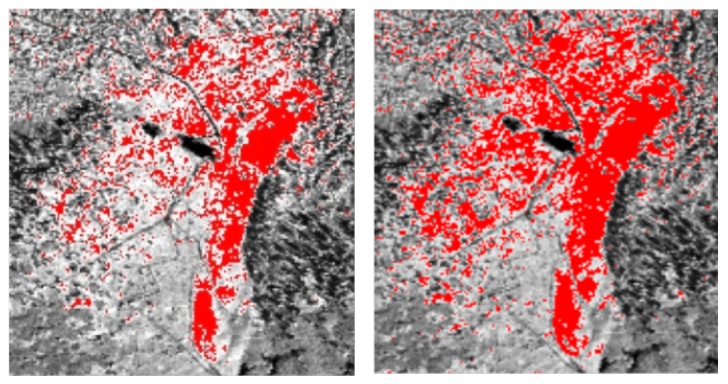

Figure 5. Thresholding of LSU and MF classification values. From the left: an abundance map of porphyritic granite, threshold 5.5, threshold 5.0, threshold 4.5. Maximum value 7.2 (photographs: Monika Mierczyk) 


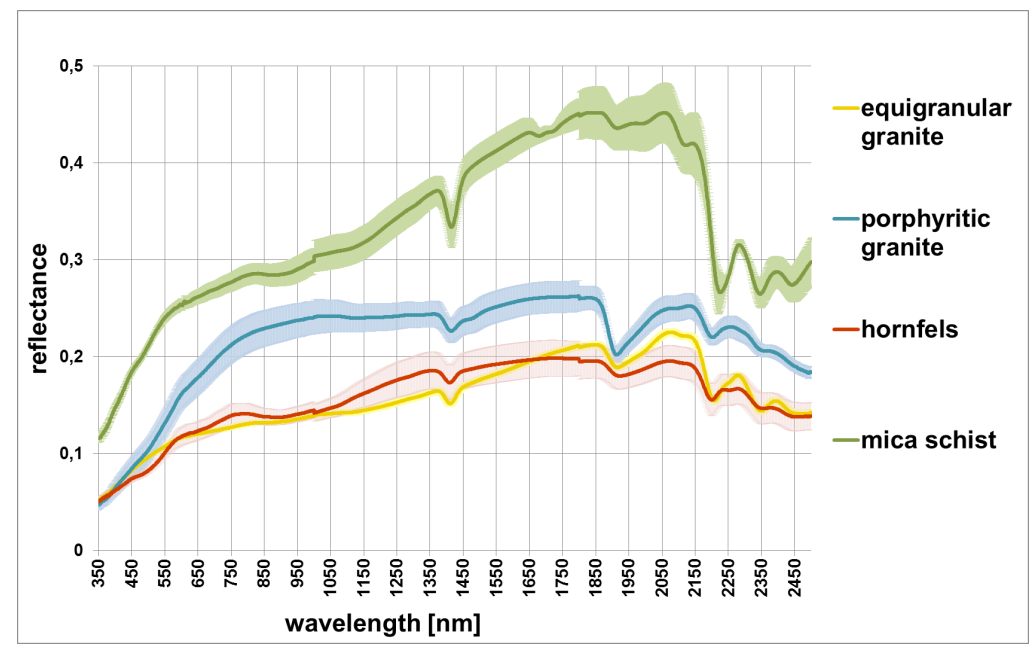

Figure 6. Spectral characteristics of rocks with standard deviations. The divergence in the spectral value curves of the rock samples proves that all rock samples are statistically different

Table 1. The producer's accuracy of the three images for three spectral algorithms

\begin{tabular}{|c|c|c|c|}
\hline $\begin{array}{c}\text { SAM } \\
\text { equigranular } \\
\text { granite } \\
\text { porphyritic granite } \\
\text { accuracy }\end{array}$ & $\begin{array}{c}\text { Producer's } \\
\text { accuracy }\end{array}$ & $\begin{array}{c}\text { User's } \\
\text { accuracy }\end{array}$ \\
\hline $\begin{array}{c}\text { hornfels } \\
\text { mica schist }\end{array}$ & 63.5 & 54.5 & 74.2 \\
\hline $\begin{array}{c}\text { LSU } \\
\text { equigranular } \\
\text { granite }\end{array}$ & 77.8 & 77.9 & 24.3 \\
porphyritic granite & 41.7 & 41.7 & 43.2 \\
hornfels & 1.1 & 1.1 & - \\
mica schist & 46.2 & 46.2 & - \\
\hline $\begin{array}{c}\text { MF } \\
\text { equigranular }\end{array}$ & & & - \\
granite & 92.8 & 92.8 & - \\
porphyritic granite & 64.4 & 64.4 & - \\
hornfels & 58.5 & 58.5 & - \\
mica schist & 93.5 & 93.5 & - \\
\hline
\end{tabular}

The hyperspectral data allowed for the positive identification of three rock types for relatively small and difficult areas of bare ground analyses. Table 1 shows results for each line and indicates that the best results are for equigranular granite and porphyritic granite, which are represented by the relatively larger areas. On average, equigranular granite was recognized with over $75 \%$ producer's accuracy, while the Matched Filtering method recorded over $90 \%$ for both granites. Hornfels attracted a mean omission value of over $90 \%$ with SAM and LSU algorithms. The corrupted result may be explained by the limited representation of hornfels on the visible, bare ground zones and consequently having insufficient testing polygons for the classification process. According to this study, Matched
Filtering is the method with the highest accuracy and efficiency in rock identification.

The main result of the study was a set of three maps that present spectral probability of rock occurrence for each algorithm. Figure 7 shows the final result of the SAM classification and Figure 8 and 9 the particular examples of the three classification results.

From the study it can be concluded that the laboratory analysis initially confirmed the efficacy of the APEX aerial imagery, thereby opening the way for the field research. Moreover, the three methods employed in processing the hyperspectral data all produced positive results in the identification. The Match Filtering method, however, proved to be the most effective. In light of this, the Matched Filtering algorithm can be recommended for use in analogous research, along with the application of atmospheric and topographic correction.

The post-classification processes formed a significant part of the research. Generalization further increased the accuracy by approximately $20 \%$. However, the generalization process has to be optimized for every image to preserve important data. An example of clumping classes process is presented in Figure 10. Figure 10. Post classification processes. From the left: raw classification image, majority analysis, majority analysis and clump classes.

Discussion and conclusions

This study focused on the detection of equigranular granite, porphyritic granite and mica schist. Comparable types of rocks in northern-west China, such as potash granite, granite, carboniferous porphyrite or limestone, were analysed by the Zhang and Li classification using two algorithms (SAM and MF) and were executed on a Hyperion image (Zhang \& Li 2014). The research showed that similar numbers of pixels in testing and verifying polygons as well as similar types of rocks can provide analogous results for classification accuracy (table 2).

Since both studies recorded similar accuracy values by applying similar work procedures and spectral algorithms, the methods of this study appear to satisfy the principle of reliability. The application of which is therefore recommended for any further studies in the field.

Much research on geological mapping focuses on homogenous rock. Using aerial and satellite images, and laboratory data combined with the SAM (Charou et al. 2007; 


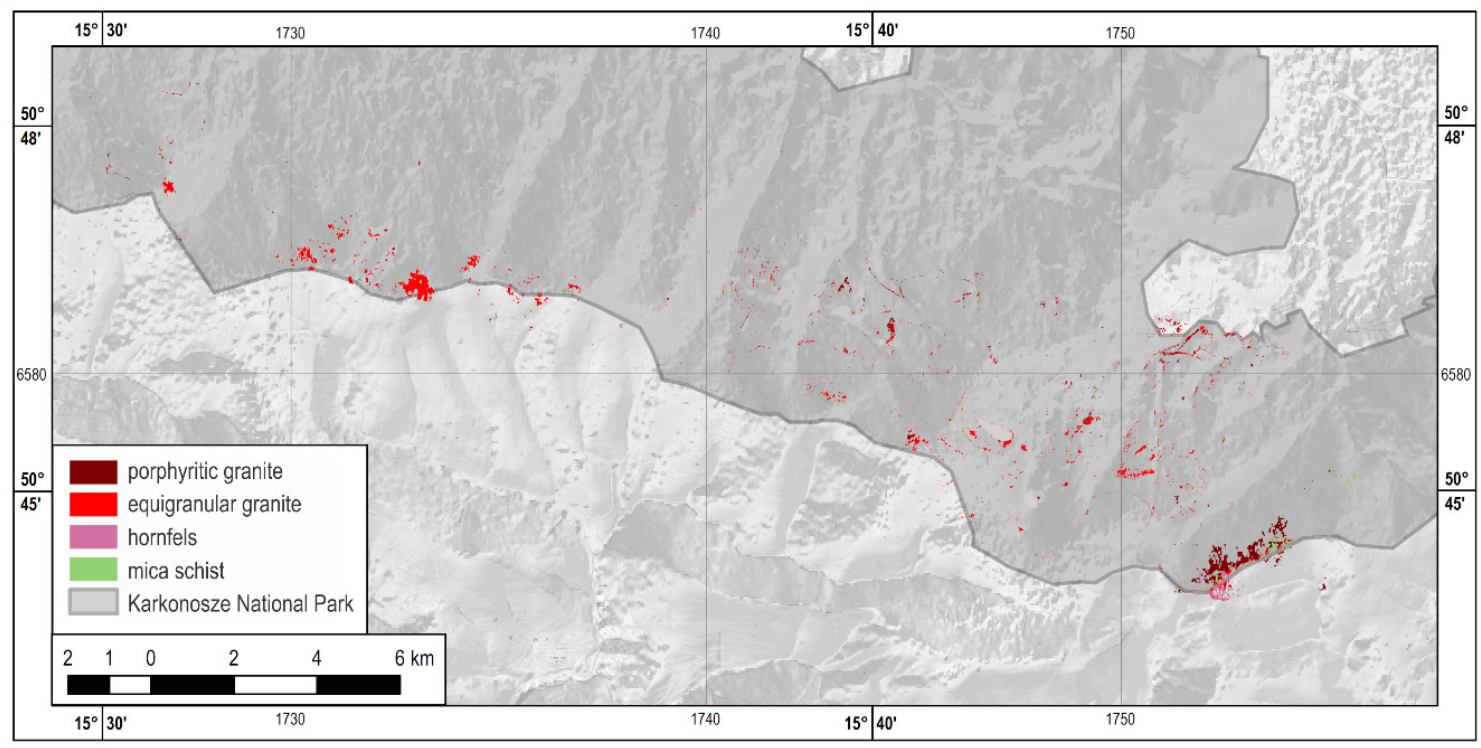

Figure 7. Matched Filtering Classification

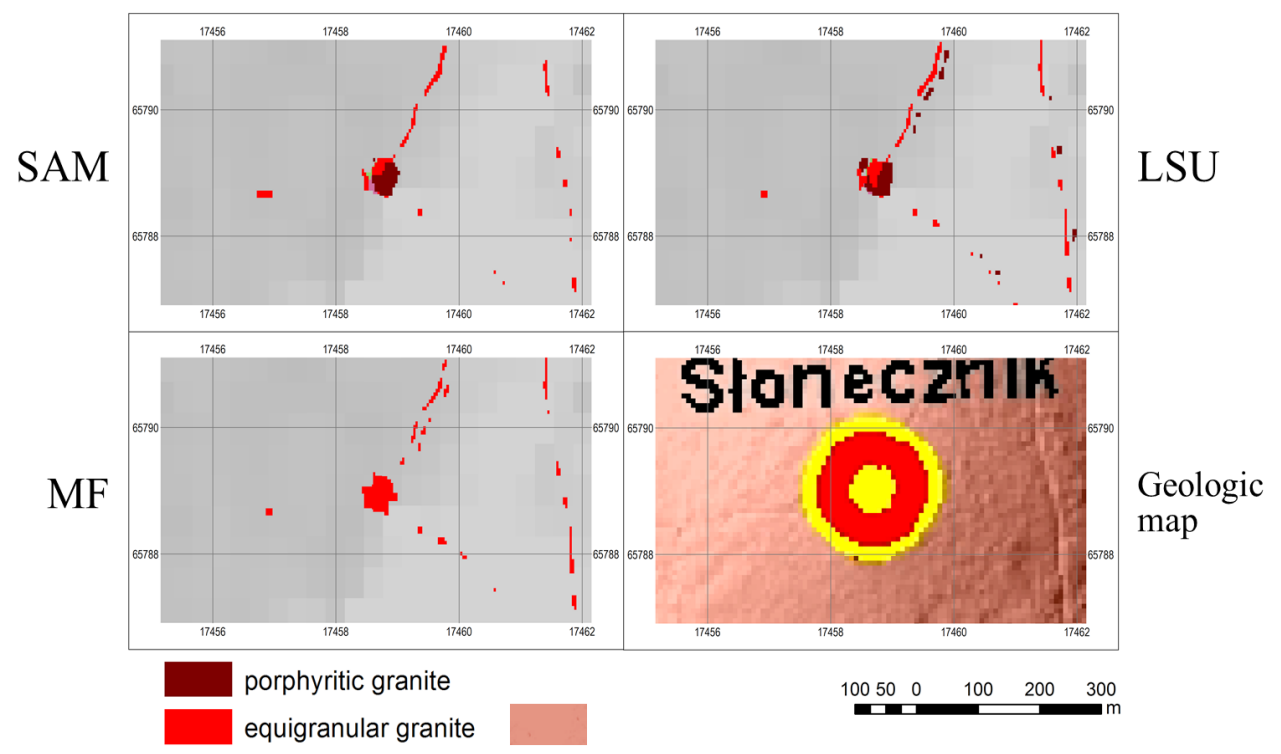

Figure 8. 'Slonecznik' rock: examples of 3 classification results. According to the geological map the area of 'Slonecznik' peak is covered by equigranular granite

Table 2. Producer's accuracy assessment for Zhang \& Li's (2014) and this research

\begin{tabular}{|c|c|c|}
\hline Classification algorithm & $\begin{array}{c}\text { producer's accuracy for equigranular } \\
\text { granite/porphyritic granite }\end{array}$ & $\begin{array}{c}\text { producer's accuracy for granite/potash } \\
\text { granite }\end{array}$ \\
\hline SAM & $77 \% / 93 \%$ & $68 \% / 68 \%$ \\
\hline MF & $54 \% / 64 \%$ & $67 \% / 71 \%$ \\
\hline
\end{tabular}




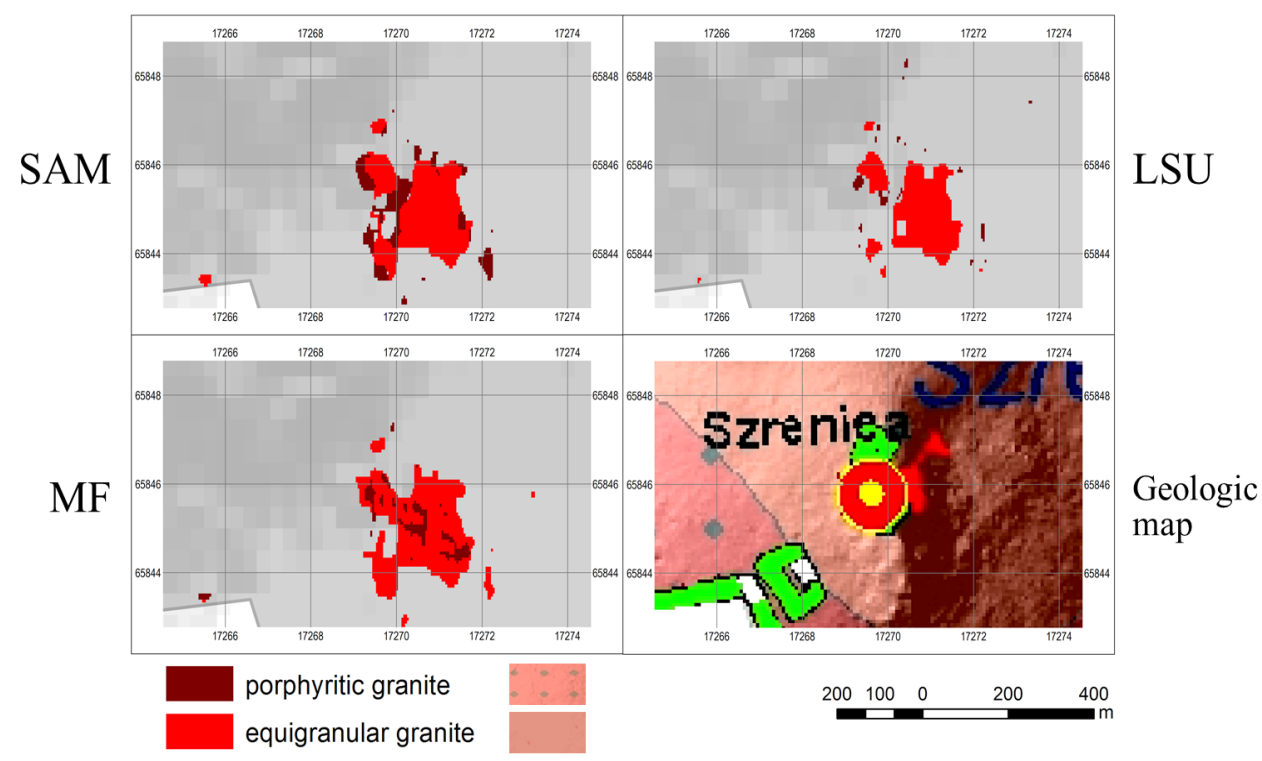

Figure 9. 'Szrenica' peak: examples of 3 classification results and a geologic map. According to the geological map the area of 'Szrenica' peak is covered by equigranular granite
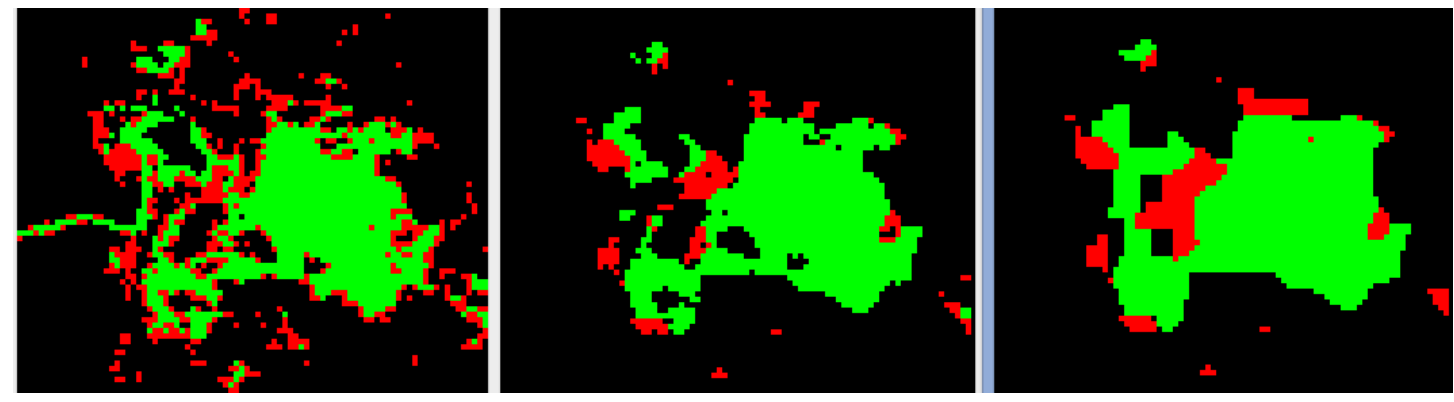

Figure 10. Post classification processes. From the left: raw classification image, majority analysis, majority analysis followed with clump classes

Farooq et al. 2014), LSU and MF (Charou et al. 2007; Littlefield \& Calvin 2013) image algorithms it is possible to achieve satisfactory results.

Main conclusions of the research:

equigranular granite is recognized with over $75 \%$ accuracy, hornfels are underestimated by over $90 \%$ with SAM and LSU algorithms - the main reason for this is a small area of interest,

- $\quad$ Matched Filtering is the method with the highest accuracy and efficacy for rock identification; this technique strengthens the response of the known endmember and reduces the response of unknown background noise, and thus improves results for relatively small testing areas; moreover threshold values created by the user allowed for sufficient classification results,

- the generalization process has to be optimized for every image to keep important data,

- analysing images without atmospheric correction might corrupt the analysis and can lead to incorrect results on shaded hillsides and areas of water, laboratory measurements initially confirmed the utility of the APEX aerial imagery for further analyses,

- hyperspectral data enabled satisfactory identification of the chosen rocks.

\section{Aknowledgements}

The authors would like to thank the curator of the Geological Museum of the University of Warsaw, Dr Marek Stępisiewicz for his support and help with the spectrometric measurements, as well as his informative lecture about the specimens and geological composition of The Karkonosze Mountains. We also thank the German Aerospace Centre (DLR) and Belgian VITO for taking, and giving permission for the use of, the aerial photos. This work was part of the Hyperspectral Remote Sensing for Mountain Ecosystems (HyMountEcos), a project of the European Facility For Airborne Research Transnational Access (EUFAR TA). 


\section{References}

Adams, JB, Sabol, DE, Kapos, V, Filho, RA, Roberts, DA, Smith, MO \& Gillespie, AR 1995, 'Classification of Multispectral Images Based on Fractions of Endmembers: Application to Land-Cover Change in the Brazilian Amazon', Remote Sensing of Environment, Vol. 52, pp. 137-154.

Aleksandrowski, P, Knapik, R, Jała, Z \& Krakowski Z 2009, 'Lokalizacja i waloryzacja geostanowisk Karkonoskiego Parku Narodowego i jego otuliny na tle mapy geologicznej', Pracownia GIS i Pracownia Naukowa Karkonoskiego Parku Narodowego.

Belward, AS 1991, 'Spectral characteristics of vegetation, soil and water in the visible, near-infrared and middleinfrared wavelengths', Remote sensing and Geographic Information Systems for resource management in developing countries, Kluwer, pp. 31-53, Dodrecht, Netherlands.

Charou, E, Stefouli, M \& Cheliotis, I 2007, 'Geological formation identification using hyperspectral imagery of Naxos island', conference papers, pp. 344-352.

Clark, RN 1999, 'Chapter 1: Spectroscopy of Rocks and Minerals, and Principles of Spectroscopy, Manual of Remote Sensing', Remote Sensing for the Earth Sciences, John Wiley and Sons, Hoboken, USA, vol. 3, pp. 3-58.

Cudahy, TJ, Hewson, R, Huntington, JF, Quigley, MA \& Barry, PS 2001, 'The performance of the satellite-borne Hyperion Hyperspectral VNIR-SWIR imaging system for mineral mapping at Mount Fitton, South Australia', Geoscience and Remote Sensing Symposium, Sydney 913 July, vol. 1.

Farooq, S \& Govil, H 2014, 'Mapping Regolith and Gossan for Mineral Exploration in the Eastern Kumaon Himalaya, India using hyperion data and object oriented image classification', Advances in Space Research, vol. 53/12, pp. 1676-1685.

Gabr, S, Ghulam, A \& Kusky, T 2010, 'Detecting areas of highpotential gold mineralization using ASTER data', Ore Geology Reviews, pp. 59-69.

Goetz, AFH, Vane, G, Solomon, JE \& Rock, BN 1985, 'Imaging Spectrometry for Earth Remote Sensing', Science, vol. 228, nr 4704, pp. 1147-1153.

Kozłowski, A \& Sachanbiński, M 2007, 'Karkonosze intragranitic pegmatites and their minerals', Granitoids in Poland, AM Monograph, no. 1, pp. 155-178.

Kruse, FA 1996, 'Identification and mapping of minerals in drill core using hyperspectral image analysis of infrared reflectance spectra', International Journal of Remote Sensing, vol. 17, no. 9 , pp. 1623-1632.
Kruse, FA, Perry SL \& Caballero A 2006, 'District-level mineral survey using airborne hyperspectral data, Los Menucos, Argentina', Annals of Geophysics, vol. 49, no 1, pp. 83-92.

Lau, IC, Cudahy, TJ, Heinson, G, Mauger, AJ \& James, PR 2003, 'Practical applications of hyperspectral remote sensing in regolith research', Advances in Regolith, Proceedings of the CRC LEME Regional Regolith Symposia, Australia, pp. 249-253

Littlefield, EF \& Calvin, WM 2013, 'Geothermal exploration using imaging spectrometer data over Fish Lake Valley, Nevada', Remote Sensing of Environment, vol. 140, pp. 509-518.

Macko, S 1970, 'Świat roślin Karkonoskiego Parku Narodowego', Wrocławskie Towarzystwo Naukowe, p. 37.

Martini, B, Silver, E, Pickles, W \& Cocks, P 2003, 'Hyperspectral Mineral Mapping in Support of Geothermal Exploration: Examples from Long Valley Caldera, CA and Dixie Valley, NV, USA', Amber Scientific Papers.

Shalaby, MH, Bishta, AZ, Roz, ME \& El Zalaky, MA 2010, 'Integration of Geologic and Remote Sensing Studies for the Discovery of Uranium Mineralization in Some Granite Plutons, Eastern Desert, Egypt', Journal of King Abdulaziz University: Earth Sciences, vol. 21, no. 1, pp. 125.

Yuhas, RH, Goetz, AFH \& Boardman, JW 1992, 'Discrimination Among Semi-Arid Landscape Endmembers Using the Spectral Angle Mapper (SAM) Algorithm', Summaries of the $4^{\text {th }}$ JPL Airborne Earth Science Workshop, JPL Publication, USA, pp. 147-149.

Zagajewski, B, Jarocińska, A \& Olesiuk, D 2010, 'Methods and Techniques of Geoscience Research', WGiSR University of Warsaw.

Zayas-Santiago, CC 2009, 'Application of Linear Spectral unmixing to Enrique reef for classification', Caribbean Journal of Science, pp. 1-18.

Zhang, X \& Li, P 2014, 'Lithological mapping from hyperspectral data by improved use of spectral angle mapper', International Journal of Applied Earth Observation and Geoinformation, vol.31, pp.95-109. 